\title{
Sobre la paz y la justicia social
}

Por Raúl Gustavo Ferreyra ${ }^{1}$

Diálogo con ideas de Arturo E. Sampay ${ }^{2}$

Ciudadanos y ciudadanas:

Me siento profundamente honrado por la invitación.

Mi reconocimiento a los organizadores y a los asistentes a este evento que congrega a más de quinientas personas. Personalmente, conmueven las expectativas que se infieren a partir de semejante auditorio concertado para esta reunión académica.

El objetivo central de la exposición es ligar la cotización de la paz con los parámetros de la justicia social. Dialogar con ideas de Sampay y traer sus tesis sobre la materia en directo, todo en directo, confronte con la realidad cotidiana de la Argentina. En concreto, intento mostrar cómo, por un lado, la injusticia social creciente actualmente en la Argentina desafía la franca serenidad de su paz relativa comunitaria, y, por otro, esbozar las razones por las que la justicia social constituye un deber de un Estado constitucional que garantice la paz relativa de una comunidad de ciudadanos igualmente libres.

Cumpliré los fines antedichos, siempre en homenaje al tiempo concedido para disertar. Divido la exposición en seis secciones: I. Memoria, II. ¿Pretextos?, III. Textos sobre la paz, IV. Textos sobre la justicia social, V. Prospecto, y VI. Comentario final. Intento, pues, concretar la ilustración pretendida.

\section{Memoria}

\section{I.1. Datos}

Siempre que trazamos una reconstrucción biográfica concluimos en un estado de cosas insatisfactorio por su falta de completitud. En tal línea de pensamiento, conocemos pocos atributos de la persona, y los que serían capaces de sostener nuestras afirmaciones o son débiles o son frágiles, porque son suficientemente conocidos.

Por regla general, al aludir a una "biografía", se espera que el disertante exponga sobre hechos que no son o no fuesen simplemente textos. Éstos son conocidos; los hechos constitutivos de la biografía, poco o nada. Ahora, doy por ciertos determinados hechos de los que me fío por entero. Así, sólo hago una sucinta relación de los episodios biográficos de Arturo Enrique Sampay.

Nació en la ciudad de Concordia, Provincia de Entre Ríos, el 28 de julio de 1911. Falleció aquí, en La Plata, el 14 de febrero de 1977. Durante su vida fue concejal en Concordia, Fiscal de Estado de la Provincia de Buenos Aires, miembro de la Asamblea Constituyente de 1949 y conjuez de la Corte Suprema de Justicia de la Nación. Se recibió muy tempra-

${ }^{1}$ Profesor titular de Derecho Constitucional, Facultad de Derecho, Universidad de Buenos Aires (UBA). Doctor en Derecho (UBA).

${ }^{2}$ Texto de la disertación oral realizada el 17/4/2017, en el Salón de los Espejos, Facultad de Derecho de la Universidad Nacional de La Plata en el "Homenaje a Arturo Enrique Sampay a 40 años de su partida. Hacia una nueva Constitución”. Deseo agradecer, en especial la invitación de Santiago E. Alí Brouchoud y de Guillermo R. Moreno. En prensa: Revista Derechos en Acción (ISSN 2525-1678), La Plata, otoño de 2017. 
namente de abogado y viajó a Europa. Durante esa estancia se familiarizó enormemente con las doctrinas jurídicas de su época. Estudió en Milán, Zúrich y París. Se desempeñó como profesor de Derecho Constitucional y Derecho Político aquí, en esta Facultad, y en la Facultad de Derecho de la UBA. También enseñó en Bolivia y Uruguay.

\section{I.2. Obras}

Por definición, los textos hablan claramente de la persona del escritor y su contexto. Con bastante habitualidad, el jurista elige como escenario para su reflexión su propia vida insertada en su propio mundo cotidiano. Un texto de doctrina jurídica en general, o de dogmática constitucional en particular, no debería constituir una ficción. Nótese que los juristas, por un lado, y dramaturgos, cuentistas y novelistas por el otro, tratan siempre de registrar casi todo en sus textos. Y, así, que el texto sea o funcione como una partitura plena de proposiciones jurídicas o drama teatral donde siempre todo queda registrado, excepto la realización. Empero, los textos de dogmática jurídica no tendrán, acaso, nada de ficción, porque su objeto preciso, el Derecho objetivo, puesto en la realidad nunca debería cobrar esa naturaleza, aunque, a veces, pareciera que se emparentan con tal filiación. De modo irremediable, entonces, por sus frutos se puede conocer al jurista y al mundo, cuya comprensión, ya sea en forma de descripción o de prescripción, colma, por regla genuina, espacios vigorosos y trascendentes de su existencia perecedera.

Hace falta una sesuda y actualizada "bio-bibliografía" de la obra de Sampay. La mayoría de las personas aquí presentes son estudiantes de grado; me gustaría que los estimule la propuesta. Simplemente, una idea para que algunos acepten la tarea. La reforma constitucional de 1949 ha pretendido ser eliminada, pulverizada de la historia. Quizá, por ello, semejante acción se haya intentado con la prolífica obra escrita de Sampay. Hay que rescatar y ponderar, con celeridad y claridad, cada uno de los eslabones de su producción científica, que abarcó 40 años de su existencia. Produjo todo tipo de escritos académicos y políticos: libros, artículos, notas, opúsculos y meros textos de opinión.

A continuación, sólo menciono doce obras, probablemente, las más representativas (pese a que esta calificación siempre es o dudosa o equivocada); varias de ellas observan alguna residencia peculiar en estas escrituras:

- La Constitución de Entre Ríos (1936).

- La filosofía del Iluminismo y la Constitución argentina de 1853 (1944).

- Introducción a la Teoría del Estado (1951).

- El Derecho de resistencia (1938).

- Las ideas políticas de Juan Manuel de Rosas (1970).

- Las constituciones de la Argentina entre 1810 y 1972 (1975).

- La declaración de institucionalidad en el derecho uruguayo (1958).

- Informe. Miembro informante Convención Nacional Constituyente (1949).

- La crisis del Estado de Derecho liberal burgués (1942).

- La filosofía del artículo 19 de la Constitución Nacional (1966).

- La doctrina tomista de la función social de la propiedad en la Constitución de Irlanda de 1937 (1940).

- Constitución y pueblo (1974). 


\section{I.3. Influencias en el pensamiento de Sampay}

Las listas de este tipo son abiertas y presuponen siempre un final similar. Sólo tienen por objeto textos de personas que han incidido en la formación del escritor. Sampay fue un erudito, es decir, una "persona que conoce con amplitud los documentos relativos a una ciencia o arte" (según define el DRAE). Leía y comprendía varias lenguas latinas y no latinas.

Para evidenciar las influencias más destacadas en la formación de su aparato teórico, tomaré dos obras de las mencionadas, que se eligen para determinar cierta filiación mayor en la obra del autor elogiado.

Su obra La crisis del Estado de Derecho liberal burgués tiene cerca de 400 páginas. Allí se demuestra una notable influencia de Santo Tomás de Aquino. El libro contiene, además, más de 400 autores citados en notas a pie de página, cuerpo principal o bibliografía.

Su obra Introducción a la Teoría del Estado tiene más de 400 páginas. Aquí la influencia de Aristóteles se hace sentir de modo distinguido. También, cerca de 400 autores citados en notas a pie de página, cuerpo principal o bibliografía.

\section{II. ¿Pretextos?}

Los juristas, en sus ensayos teóricos, intentan describir un problema concreto y definir su solución mediante una tesis determinada o respuesta específica. Pondré en escena dentro de las próximas secciones (III y IV, respectivamente) dos ideas de Sampay. Luego, ilustraré por mi propia cuenta dentro del propio territorio de las secciones III y IV. Si correspondiese, dicha alocución contendrá: "ideas fecundas e irresueltas", cuando son expresadas por el disertante que suscribe este mismo texto. ¿Por qué? Hay presupuestos que en esta disertación no serán considerados por falta de tiempo y espacio, pero inciden en todo cuanto se opina en las secciones siguientes.

La Argentina padece, actualmente, una crisis relevante en las bases de su institucionalidad. Las ciudadanías durante muchos años han discutido si es mejor el gobierno de los hombres o el gobierno de la constitución. En esa díada, elijo exclusiva y excluyentemente la gobernanza de la Ley fundamental. Sin embargo, como se aprecia más adelante, aunque la normatividad constitucional sin reservas constituye un paso destacado para la ordenación de la coexistencia ciudadana comunitaria, no es suficiente. Porque esas mismas reglas constitucionales favorecen la sustanciación de modernos despotismos degenerados que impiden, lógicamente, la tutela de los intereses de todos.

Las constituciones tienen cuatro partes: simples enunciados; derechos, bienes y deberes fundamentales; organización y control del poder, y, finalmente, prescripciones sobre la variación constitucional. La Argentina, para su sistema político constitucional, adopta el "monopresidencialismo", un anticuado carro inventado en el siglo XVIII y que tiene una sola rueda. Si funciona, arrasará con energía suprema contra cualquier autoridad o ciudadanía erguida que se le enfrente. En caso de no funcionar, su crisis se transmite a la comunidad: parálisis, bloqueo y desgobierno. ${ }^{3}$

\footnotetext{
${ }^{3}$ V. FERREYRA, Raúl Gustavo: "Presidencia o monarquía", en Revista Comunidad y desarrollo en la batalla cultural, agosto de 2016, p. 8 (ISSN 1668-3579).
} 
El monopresidencialismo es un sistema de gobierno maldito que deposita el poder público en un oficial público, denominado, a la sazón presidente de la República. Por ello, cuando asume y durante la perduración de su representación instituyente, no es una mera hipótesis quimérica que el oficial público se desquicie y pulverice el fragmento constitucional referido a los derechos, bienes y deberes fundamentales. Se cae a pedazos la idea de "alternancia democrática", porque este "príncipe absolutista" juzga que puede borrar de un plumazo las conquistas jurídicas captadas por la constitución. Se le da todo el poder por medio de este último instrumento y se produce la corrosión del sistema de gobierno. El oficial público y su elenco de gobierno se siente arropado para dejar en suspenso o derogar transitoriamente, hasta nuevo aviso, el fragmento - insisto- destinado a determinar la línea de acción gubernativa: derechos, bienes y deberes fundamentales. Éstos ya dejarán de ser tales, porque son considerados, en el mejor de los casos, como bonitas postales.

Sin adelantarme, en 1949, Sampay pensó que la estructura del poder ejecutivo (monopresidencial), con "algunos ajustes requeridos por nuestro tiempo", tal como había sido concebida por el poder constituyente en 1853, era lo "suficientemente vigorosa y ágil como para seguir cumpliendo la función que al Estado atribuyen las reformas de la parte dogmática" ${ }^{\text {. Desde }} 1951$ hasta 2015, el pueblo argentino ha concurrido a elegir a un "oficial público" para el cargo de "monopresidente" en trece oportunidades; en dos de ellas con proscripción del partido político mayoritario. Más de la mitad de los oficiales públicos elegidos no pudieron cumplir su representación, porque golpes civiles o golpes civiles-militares-eclesiásticos lo impidieron fatal y criminalmente. El actual período del oficial público a cargo de la institución presidencial fenece en 2019; nadie en su sano juicio puede derivar de estas escrituras ninguna intención, directa o indirecta, para derrocar su gobierno. Debe culminar, por de pronto, su institución como presidente de la Argentina, en tiempo y forma, en diciembre de 2019.

Se hace necesario estudiar nuevas bases de certidumbre para la reforma de la institucionalidad de la Argentina. La paz y la dicha del pueblo son los estadios más transcendentes. Hacia allí se dirige la comprensión en los próximos apartados, a tal punto que en el apartado $\mathrm{V}$ propiciaré una regla de constitutione ferenda. A raíz de ello, no disertaré sobre el sistema de gobierno en cuestión. Sin embargo, quiero dejar algo en claro: hasta el día de hoy, fatalmente, no hay norma jurídica que pueda impedir o aliviar los desmanes que produzca sobre la tranquilidad y beatitud ciudadana un mal gobierno de un oficial público en un esquema de poder monopresidencialista.

\section{Textos sobre la paz}

\section{III.1. Salvaguarda y dicha de los ciudadanos en la obra de Sampay}

El supremo bien público - dijo Sampay - reside en lograr que los ciudadanos vivan virtuosamente. Empero, sin paz interior, con carencia de los bienes necesarios para sus

\footnotetext{
${ }^{4}$ SAMPAY, Arturo E.: "Discurso del miembro informante de la mayoría de la Comisión Revisora de la Constitución”, en Las Constituciones de la Argentina, 1810-1972, Buenos Aires, Eudeba, 1975, p. 489.
} 
tentarse y puestos a merced de la explotación de "enemigos exteriores", el ciudadano no puede vivir libremente con miras a ser virtuoso, es decir, a "planificar su naturaleza de ser racional". ${ }^{5}$

También en el texto citado, Sampay sostuvo que el Estado, para satisfacer esos bienes públicos, actúa a través del orden jurídico que sanciona. Concluyó este argumento con cita de Cicerón: las leyes se inventaron para salvar a los ciudadanos y a los Estados y con vistas a alcanzar la tranquilidad y la felicidad de los hombres ${ }^{6}$.

Leamos más a Sampay. En el trabajo citado también expresó que deben ser objeto de precisión los bienes públicos que persigue el Estado, es decir, los fines naturales de su razón de ser. Así — redondeando- expuso que, en primer lugar, el Estado tiende a que los hombres, una vez congregados, vivan en paz; en segundo término, procura que esos hombres, unidos por el vínculo de la paz, obren bien, esto es, vivan según la virtud. Por todo ello, el Estado se debe ocupar de que la comunidad esté abastecida de las "cosas imprescindibles" para "vivir bien"

Para nuestro autor elogiado, el orden de realización de los bienes públicos, el fin superior de las leyes reside en la salvación de la comunidad, que se cumple "al asegurarle su paz interior", pues la anarquía disuelve las sociedades, y al preservarla de los enemigos exteriores, ya que éstos buscan el aniquilamiento del propio ser de la comunidad ${ }^{8}$.

Todo este aparato de doctrina fue llevado hasta sus últimas instancias conjeturales. De acuerdo con Sampay, atento a que el legislador debe ante todo poner en su obra la intención de "salvaguardar" la "comunidad", los que ejercen los supremos poderes del Estado están obligados a interpretar las leyes con ese sentido primordial. En el caso concreto en que una ley no resulte conducente a ese supremo bien público, los gobernantes están dispensados de cumplirla, si para la "salvación" del Estado no queda otra solución." Hasta aquí, sus ideas. En otros sitios también expuso sobre la materia. ${ }^{10}$ Sencillamente, por las razones presentadas en la sección I, se escogen las ideas de un sitio preferente que no inhibe ni descarta las cualidades de otros trabajos.

\footnotetext{
${ }^{5}$ SAMPAY, Arturo E.: “Actos políticos no justiciables", en La declaración de inconstitucionalidad en el derecho uruguayo, Montevideo, Medina, 1958, p. 83.

${ }^{6}$ Ibíd., p. 83. La cita de Cicerón: Las Leyes, Libro II, 11.

${ }^{7}$ Ibíd., p. 82.

${ }^{8}$ Ibíd., p. 83.

${ }^{9}$ Ibíd. y loc. cit.

${ }^{10}$ Sampay también se explayó sobre el "ideal de la paz" en "El Derecho Internacional de la Paz en la Constitución de Irlanda", en Revista de Derecho, Administración y Jurisprudencia, Montevideo, septiembre de 1939, pp. 257 y ss. Seguramente quedó impresionado por el art. 29 de la Constitución Irlandesa de 1937, que en su apartado 1 dispuso: "Irlanda proclama su identificación con el ideal de paz y cooperación amistosa entre las naciones, fundando en la justicia y la moral internacionales".
} 


\section{III.2. La tranquilidad comunitaria en la Argentina actual}

Desde hace unos años, la Argentina sufre una agresión que se concreta de diferentes modos, quizá en sus manifestaciones más evidentes: pago indebido a los "fondos buitres"; deuda externa contraída sin control ni límites; suma del poder público para la explotación sojera y minera; represión a sus ciudadanos (en especial, a la protesta social); aumento de tarifas de los servicios públicos; precarización del empleo de maestros y médicos, y otros trabajadores de la educación y de la salud; caída del empleo; freno a la obra pública; industria nacional a merced del Poder Ejecutivo Nacional; manejo antojadizo y extorsivo de los recursos del erario federal.

El Estado constitucional, la mayor invención del hombre para la congregación de las coexistencias y la expectativa de una paz serena, se encuentra jaqueada. Colocada en entredicho, al menos la robustez de la paz social. El oficial público dispone políticas irracionales. Cualquier ciudadano en el auditorio podría preguntarse con legitimidad: “¡por qué?".

La Argentina se encuentra encadenada a los "poderes salvajes ${ }^{11}$ supra-estatales", económicos y financieros, que originan que dos de cada tres argentinos sean desposeídos; ya sea pobre o población vulnerable a punto de serlo. Esa agresión provoca un severo proceso de desconstitucionalización del sistema político de la Argentina, que ya padece una inmunodeficiencia genética irrecuperable e irreversible: el monopresidencialismo. La dirección suprema de la ordenación estatal no reside en los ciudadanos que integran el pueblo, quienes, por lo general, poseen ideas diversas y no coincidentes. Hay una letra constituyente que instituye el mono presidencialismo, un modelo centrado en unidad de régimen y por eso ariete canalla del pluralismo y la concertación democráticas.

La conducción política que asumió la conducción del Estado argentino el 10 de diciembre de 2015 hace que la soberanía política se encuentre en discusión. Los poderes hegemónicos extranjeros fuerzan a nuestros ciudadanos a un "esclavismo social" que se define en gran escala, según la comprensión del Raúl Zaffaroni ${ }^{12}$. La expansión, el agrandamiento del espacio de "dominación colonial" del capitalismo trans o multinacional, coloca en cuenta regresiva la paz interna. Porque se trata de una agresión franca: la condena al subdesarrollo a nuestros ciudadanos bien intencionados.

La idea del Estado, la idea de la comunidad política por excelencia o su mayor expresión, encuentra explicación y justificación en la "idea de una totalidad" (el propio Estado) que mantiene unidas las individualidades ciudadanas (las partes), que de otro modo estarían en perpetuo conflicto entre ellas. ${ }^{13}$ La unidad del todo es fertilizada y asegurada por la constitución. Quien tiene el poder de hacer las leyes es el pueblo soberano por intermedio de sus representantes o en forma directa por las vías que constitucionalmente

\footnotetext{
${ }^{11}$ FERRAJOLI, Luigi: Poderes salvajes. La crisis de la democracia constitucional, Trotta, Madrid, 2011.

${ }^{12}$ V. ZAFFARONI E. Raúl: “Constitución y procesos de transformación”, en el texto de su disertación para este mismo encuentro académico, gentilmente cedido por su autor.

${ }^{13}$ BOBBIO, Norberto: El futuro de la democracia, Barcelona, Planeta, 1985, pp. 167-171.
} 
se contemplen y decidan. Así, la soberanía política ciudadana queda emplazada como presupuesto de la paz relativa interna de la comunidad.

La formación de la soberanía y su desarrollo alienta la configuración de un Estado constitucional independiente, es decir, una coexistencia ciudadana pacífica en la que se rechace cualquier modelo de sujeción o imposición colonial. Si los ciudadanos argentinos se encuentran forzados a trabajar para el "capitalismo salvaje sin fronteras", este dominio debilita las posibilidades de un Estado que constituya la verdadera ordenación de individuos libres. Cuanto menos Estado constitucional, menos soberanía ciudadana y mayor comunidad colonizada.

En definitiva, se produce un acoso a la paz comunitaria, en un recorrido significativamente regresivo. Zaffaroni alude - y tiene razón - a que la "programación constitucional del Estado" ha sido tan defectuosa que nos dejó en situación de "extrema vulnerabilidad frente a los embates del colonialismo"14.

Ninguna constitución edificará un dique absoluto a estos embates. Pero disponemos de un texto que autoriza esta ausencia de equilibrio. Una constitución es un "instrumento de paz duradero", aunque, si guarda silencio de sepulcro o favorece la expoliación de las generaciones de ciudadanos, es un instrumento defectuoso que merece ser estudiado y reformado.

\section{Textos sobre justicia social}

Sampay mantuvo un diálogo muy cercano con la teoría de la justicia esbozada por Aristóteles. Además, en 1931, cuando tenía tan solo 20 años, se promulgóla Carta Encíclica Quadragesimo Anno. En ese texto, por primera vez, se introduce en el vocabulario papal la idea de "justicia social". La norma sobre la justicia social es referida en seis ocasiones en la escritura papal (ver apartados 58, 71, 74, 88, 101 y 110). Pienso, pues, que la unión de la teoría de Aristóteles y la Encíclica conformaron las proposiciones capitales de Sampay. Además, en 1937 se promulgó la Constitución de la República de Irlanda, que, en buena medida, recogió hallazgos bendecidos por la Encíclica. Sampay publicó en 1940 un trabajo sobre la función social de la propiedad en la Constitución irlandesa de 1937.

La Constitución argentina de 1949 alude en dos ocasiones a la noción de justicia social. En primer lugar, en el recordado propósito anclado en el Preámbulo: "Nos, los representantes del pueblo de la Nación Argentina (...) para nosotros, para nuestra posteridad y para todos los hombres del mundo que quieran habitar el suelo argentino; ratificando la irrevocable decisión de constituir una nación socialmente justa, económicamente libre y políticamente soberana.... En segundo lugar, en el benemérito artículo 40: "La organización de la riqueza y su explotación tienen por fin el bienestar del pueblo, dentro de un orden económico conforme a los principios de la justicia social".

Sampay también hace referencia a ella en su recordado "Discurso" como miembro informante del Despacho de la Comisión Revisora de la Convención Nacional Constituyente de 1949:

Por justicia social, señor presidente, debe entenderse la justicia que ordena las relaciones

${ }^{14}$ ZAFFARONI, E. Raúl: ob. cit. 
recíprocas de los grupos sociales, los estamentos profesionales y las clases con las obligaciones individuales, moviendo a cada uno a dar a los otros la participación en el bienestar general a que tienen derecho en la medida en que contribuyen a su realización. ${ }^{15}$ Un cuarto de siglo después, el 13 de setiembre de 1974, nuevamente Sampay define y realiza su concepción sobre justicia social, en la causa "Bercaitz", al intervenir en el cargo de conjuez de la Corte Suprema de Justicia de la Nación. Se trata de la primera ocasión en la que el Más Alto Tribunal de la República Argentina menciona a la justicia social en uno de sus fallos judiciales.

\section{IV.1. Sobre la lengua de la desposesión}

En 1852 Juan Bautista Alberdi, arquitecto de constitucionalidad de la República Argentina, dogmatizó: "La constitución debe ser hecha para poblar el suelo solitario del país de nuevos habitantes y para alterar y modificar la población actual"16. Al relacionar la superficie de la Argentina con sus habitantes, por entonces menos de 1.000 .000 de personas abrumadoramente analfabetas, se preguntó qué nombre merecía un país así conformado: "un desierto". Por consiguiente, ¿qué nombre habría de darse a la Constitución de ese país?: "La constitución de un desierto"17. Dentro del cerco de su escritura siempre mantuvo un diálogo interno: “¿Cuál es la mejor constitución que conviene al desierto?”: la que sirve para hacer que el desierto deje de serlo en el menor tiempo posible y se constituya una República en un "país poblado"18. La tesis de su escritura política puede resumirse en su frase: "gobernar es poblar".

No ingreso aquí en la semántica ni en la morfología de la citada tesis de Alberdi. Sí, en cambio, me aprovecho en parte de su pura y endurecida sintaxis. Adopto como consigna "gobernar es igualar". Tarea emprendida desde una comprensión teórica con vocación constituyente. A la pregunta “¿cuál es la mejor constitución?”, respondo: la que se oriente de modo decidido, decisivo e imparcial a terminar con la desigualdad social y convertir a la República en un país de ciudadanos igualmente incluidos.

Las dimensiones de la igualdad, con diverso significado y grado de reconocimiento, pretenden cobijar una determinada fundamentación del Estado, al equiparar por convención aspectos de las relaciones entre los hombres. La igualdad ante el Derecho significa una de sus fortificaciones. Un nuevo logro: la igualdad de oportunidades. Ambas son insuficientes porque no detienen la marcha regresiva del bienestar. Porque no hay justicia social, el tercer género, el más elevado y solidario.

\footnotetext{
${ }^{15}$ SAMPAY, Arturo E.: "Discurso del miembro informante de la mayoría de la Comisión Revisora de la Constitución, ob. cit., p. 500.

${ }^{16}$ ALBERDI, Juan Bautista: Bases y puntos de partida para la organización política de la República Arjentina, derivados de la lei que preside al desarrollo de la civilización en América del Sud $y$ del Tratado Litoral de 4 de enero de 1831, $2^{a}$ ed., correjida, aumentada de muchos parágrafos $y$ de un proyecto de Constitución concebido según las bases propuestas por el autor, Valparaíso, Imprenta del Mercurio, Santos Tornero y Cía., 1852, p. 195.

${ }^{17}$ Ibíd., p. 196.

${ }^{18}$ Ibíd.
} 
La desigualdad creciente en la Argentina, donde casi el 60 por ciento de su población es pobre o vulnerable, exhibe la existencia de dos mundos: una ciudadanía política y una ciudadanía social. Los desposeídos, pobres y vulnerables, no disfrutan y no podrían disfrutar, con el actual estado de cosas constitucional, de una ciudadanía plena de justicia social. Quizá la política. Nunca se extinguirá por costumbre natural la desigualdad entre los hombres, cuyas fuentes principales y más odiosas, repugnantes y abominables, son la pertenencia a una etnia, el sexo, la edad o la clase social.

Las constituciones poseen, en general, pretensiones sobre las que fundar una cierta idea de eternidad; la de la Argentina en el siglo XIX, una república "esencialmente comercial y pastora”. A lo largo de la historia, salvo excepciones, se ha maximizado la concentración de la riqueza (tanto la yacente como la creada) y se ha descuidado, con dolo o negligencia, el crecimiento de la pobreza y la vulnerabilidad poblacional. Actualmente, en 2017, la población de la Argentina supera los 43.000.000 de habitantes; la singularidad de la situación que aquí se denuncia — pobreza y vulnerabilidad— aflige a más de la mitad de ellos. Si bien semejante desgarro no será curado sólo con normas, ellas constituyen un cuerpo de prescripciones sobre la negación o la afirmación de la justicia social. Es necesario determinar nuevos criterios sobre la igualdad en el propio cuerpo normativo del sistema de la Constitución. Las enunciaciones sobre el proceso de la igualdad actualmente en vigor han fracasado, en especial, por su insuficiencia. Normativamente, en materia de justicia social, el problema lo constituye más la ausencia de reglas, es decir, la "laguna", antes que la segura y correspondiente ineficacia de las vigentes. Se debe elaborar un Prospectus - tal como presento en el próximo apartado- sobre política constitucional que, llegado el momento constituyente, podría legitimar y favorecer la extirpación del mal: la erradicación de la pobreza. Que contemple la misión fundamental del Estado con la justicia social.

Nunca será posible destruir por completo a la desigualdad social; se la puede disminuir continuamente. Un progreso con justicia social se presenta como misión fundamental del Estado. La reducción del dualismo en los grados de la ciudadanía se la propicia con múltiples energías. Una puede provenir de un consenso básico, en nuevo auditorio regido por la Constitución en su proceso de variación. Mientras no se produzca un reparto más igual de los bienes que se deben a la naturaleza o a la industria, la lengua de las escrituras laicas ${ }^{19}$ serán mejor comprendidas por aquellos que conozcan los beneficios de una ciudadanía completa y conozcan todas sus luces. Y no habrá razón colectiva suficiente para el progreso del individuo humano y su derecho al desarrollo pleno de su personalidad en comunidad abierta.

Pensar que la justicia social deberá ser la misión fundamental del Estado significa trans-

${ }^{19}$ Según la acuñación propuesta por VALADÉS, Diego: “¿Qué hacer con la Constitución?”, en Reforma, México, 2 de febrero de 2016, disponible en www.reforma.com/aplicacioneslibre/ editoriales/editorial.aspx $? \mathrm{id}=81220 \& \mathrm{md} 5=05567 \mathrm{a} 7 \mathrm{fe} 830663 \mathrm{~d} 1 \mathrm{a} 4 \mathrm{~b} 14 \mathrm{~d} 63064 \mathrm{c} 495 \mathrm{\& ta}=0 \mathrm{dfd}-$ bac11765226904c16cb9ad1b2efe\&lcmd5=2ebc84d163eeaf4cb937892081ba9526 (consultado el 4/2/2016). 
formar la realidad. Oponerse al estado de cosas real incluye una nueva orientación y una nueva "vocación del pensamiento"20 ${ }^{20}$ plena de realismo y naturaleza auténtica, que se desarrolle en renovado auditorio ciudadano, cuya ligazón con el pasado sea el respeto estricto al proceso de variación de la Constitución federal de la República Argentina. Tal actividad puede ser alimentada con normas de la más alta jerarquía, en la inteligencia de que la norma constitucional gobierna, con justeza o sin ella, un proceso público sobre el bienestar de los individuos en la comunidad.

Propiciar un modelo que sostenga una mayor intervención del Estado en el reparto y disfrute de los bienes yacentes y que serán creados en una economía, con la misión de la justicia social, no significa un ideal perfeccionista. El Estado debe asegurar que cada individuo pueda, libremente, desarrollar su plan de vida escogido sin interferencias de ninguna clase, porque allí, con precisión, se legitima el Estado, en su juridicidad más estricta. La desigualdad social creciente se constituye en un escollo que impide el propio plan que se eligiese, desde que puede llegar a comprometer la paz relativa.

La infeliz laguna del Derecho constitucional sobre igualdad fundamental y la semejante inefectividad constitucional de las reglas sobre igualdad de oportunidades también afecta al principio de igualdad, porque la divergencia o la ausencia de normas observan su asiento en la inevitable existencia entre ser y deber ser del Derecho constitucional. El vacío debe ser completado con nuevas reglas de Derecho constitucional construidas en el ágora ciudadana, gracias al proceso de creación normativa fijado en el artículo 30 de la Constitución federal de la República.

En plena luz del día, la justicia social es una bendición laica. Por su acción se puede procurar reducir la mortificación, daño que produce la exclusión social como la pobreza o situación vulnerable semejante. Igualar fundamentalmente a nuestra ciudadanía constituiría una misión inigualable para su propio bienestar general y el de las generaciones futuras, anunciadas y protegidas desde el Preámbulo de la Constitución federal de la Argentina.

\section{PROSPECTUS ${ }^{21}$}

Las escrituras del Derecho constitucional, severamente codificadas, disponen cómo ha de gobernarse una comunidad. Instaurar en una constitución, con un solo trazo, la idealidad sobre determinados fines comunitarios constituye un acto de gobierno constituyente. Quiero decir, sin alardes, que un estado de cosas se comprende en la escritura constituyente de la constitución y otro estado de cosas se revela en el acto de gobernar cotidiano de las autoridades constituidas.

Julio Maier ha planteado que una futurible reforma constitucional debería ser “... más la coronación de un progreso en la vida social, asegurándolo hacia el futuro, que un incen-

\footnotetext{
${ }^{20}$ BADIOU, Alain: Nuestro mal viene de más lejos, Buenos Aires, Capital intelectual, 2017, p. 19.

${ }^{21}$ En 1793, Jean-Antoine-Nicolas de Caritat (Condorcet), junto a Emmanuel Sieyès y Jules Duhamel, publicaron el Journal d'instruction sociale par les citoyens. Condorcet tituló de este modo (Prospectus) a las palabras introductorias (Paris, Edhis, 1981, disponible en http://gallica.bnf.fr/ark:/12148/bpt6k97249, consultado el 7/9/2016).
} 
tivo, orden o condición para que cualquier gobierno asuma este programa”22. Coincido con su opinión. Es menester estudiar la reforma constitucional.

Así, toda reforma de la constitución contiene sólo dos tipos de reglas: de adaptación y de fomento. Ambas son igualmente prescriptivas. Desde tal perspectiva, se propicia la regla que sigue significativamente; en su interior, conviven la paz y la justicia social. No hay dudas de que se hace necesaria una intervención del Estado que detenga, racionalmente, la vertiginosa injusticia social, dado que este fenómeno tiene aptitud para socavar la tranquilidad pública, la propia salvaguarda coexistencial de la comunidad.

Pido la comprensión del auditorio ciudadano: no es posible redactar una regla sobre la paz y la igualdad fundamental, como hago más abajo, y pretender su ubicación en la cabecera de un futurible texto constitucional de ciudadanos elegidos por el pueblo, sin referirme, en particular, al nuevo montaje jurídico de un nuevo modelo sobre el sistema de gobierno de la República, que abandone al absolutismo presidencial, entre otras materias. Asumo el riesgo, e intento redondear, en una futurible regla, las ideas expuestas sobre paz y justicia social.

\section{V.1. Regla de apertura}

La soberanía reside en el pueblo, fuente de toda la autoridad del Estado, cuya orientación consiste en mantener y desarrollar la paz relativa de la comunidad. Todos sus habitantes son iguales en libertad y ante el Derecho.

La Argentina es un Estado democrático, laico y federal, basado en la protección de la dignidad humana y su misión primordial es realizar la igualdad fundamental entre todas las personas.

La República instituida por esta Constitución como forma de gobierno se orienta por el pluralismo, la participación, la publicidad y la racionalidad.

\section{V.2. Soberanía política}

A la vez, juzgo que sería interesante discutir una regla que pertenezca al Derecho constituyente del Estado y de ámbito semejante al artículo 45 de la Constitución de Irlanda de 1937:

Los principios de política social que se especifican en el citado artículo deberán servir de guía en general para el Parlamento, y su aplicación en la elaboración de las leyes irá exclusivamente a cargo del órgano congresual, sin que pueda ser revisada por ningún tribunal establecido al amparo de algún precepto de esta Constitución.

\section{Comentario final}

Así llegamos al final de este viaje. Hay una frase latina que dice Rem tene, verba sequentur (Si dominas el tema, las palabras vendrán). Agradezco la paciencia, el interés y, sobre todo, que hayan disimulado el hecho de que intenté dominar el asunto y que las palabras broten $\mathrm{o}$ abunden.

\footnotetext{
${ }^{22}$ MAIER, Julio B.: "Constitución y transformación institucional y social", preparada para este mismo encuentro y gentilmente cedida por su autor.
} 
Sampay nació en 1911. Un siglo después que Juan Bautista Alberdi. Ambos fueron los arquitectos de los mayores programas sobre la constitucionalidad de la Argentina. Alberdi, con su pluma, en el siglo XIX. Sampay, con su máquina de escribir, en el siglo XX. Guardo la febril esperanza de que ya hayan nacido, aquí, en La Plata, el grupo de juristas que estudiarán la futurible reforma del sistema constitucional federal de la República. Un cambio profundo en la Ley fundamental que la oriente, definitivamente y sin pausas, a la paz social y que tenga como misión ineludible, inclaudicable e impostergable la conjugación y el desarrollo de la igualdad fundamental entre todos los seres humanos que decidan habitar el suelo de la Argentina y elijan vivir su vida bajo su sol y con sus gentes. El Derecho constituyente que emana de un sistema debe aspirar a constituir la lengua que sostiene y desarrolla la unidad de una comunidad determinada. Esa lengua, la lengua del Derecho constitucional, configura el texto fundamental para la existencia en paz de los ciudadanos y servidores públicos. Ambos para lograr que rija o que tengan eficacia los enunciados de la lengua constituyente del Estado deben comprenderse en la escena del dominio lingüístico y deben producir una asociación recurrente, intensa y prolongada, en la aceptación y desarrollo de las determinaciones prescriptivas sobre la conducta humana. Así, en el marco de una escritura sin despotismos, la realidad comunitaria se debe encontrar abierta al discurso que contiene las palabras constituyente; la gobernanza de dicha realidad, por lo tanto, queda remitida al consenso, mayor o menor, sobre el marco de referencia que ha de referirse o preferirse a la mutualidad de las determinaciones sobre la conducta humana.

Consecuentemente, ejercer dominio sobre la producción y variación de las palabras del poder público, aunque no define por completo el dominio de la realidad, significativamente se comporta como un agente de creación y cambio. De manera coherente, pues, la existencia de los ciudadanos en la formación precisa de la lengua constituyente del Estado, debería configurar el propio dominio de realidad.

Esa lengua de la unidad, el Derecho constitucional que fundamenta al Estado, debería ser cambiada todas las veces que fuese necesario, si, acaso, sus indicaciones deónticas carecen de fortaleza para dar tranquilidad a los ciudadanos y que puedan vivir bien.

Muchas gracias. 